\title{
Evidence against a short-term-store account of long-term recency effects
}

\author{
ANJALI THAPAR and ROBERT L. GREENE \\ Case Western Reserve University, Cleveland, Ohio
}

\begin{abstract}
When subjects perform a distractor task before and after every item on a list, recall of the last item is much higher than recall of items from the middle of the list. Koppenaal and Glanzer (1990) have shown that this long-term recency effect can be eliminated by using, after the last item, a distractor task different from that used elsewhere on the list. They interpreted this finding as evidence in favor of a short-term-store account of long-term recency effects. This account is challenged by the results reported here. Practice either on the task or on time-sharing between the task and list items had little impact on the recency effect. Also, substantial recency effects were found when a different distractor task occurred after every list position. Thus, it is not true that long-term recency effects are found only when subjects have an opportunity to adapt to the distractor task. Our results are not consistent with a short-term-store account of recency effects.
\end{abstract}

In immediate free recall, subjects recall the last few items on a list better than items occupying intermediate positions (see Greene, 1986b, for a review). For many years, the standard explanation for this recency effect was that it was due to retrieval from a limited-capacity shortterm memory store (sometimes called primary memory) (see, e.g., Atkinson \& Shiffrin, 1968; Glanzer, 1972; Waugh \& Norman, 1965). Retrieval from the short-term store is relatively easy, so items still present in this buffer at the time of test are more likely to be recalled than are items that must be retrieved from a long-term store. An often-cited piece of evidence in favor of this account is the finding that recency effects can be eliminated if subjects perform a distracting activity after presentation of the last item (Glanzer \& Cunitz, 1966; Postman \& Phillips, 1965).

This short-term-store account of recency effects was challenged by results found by using the continuousdistractor paradigm employed by Bjork and Whitten (1974; see also Tzeng, 1973). In this task, the presentation of each pair of words is preceded by a distractor task. The last pair is followed by another period of distractor activity. A sizable recency effect is typically obtained. Bjork and Whitten believed that a short-term-store account of recency effects in the continuous-distractor paradigm was unconvincing, insofar as the last period of distractor activity should have fully occupied the short-term store.

How should adherents of a short-term-store account deal with these long-term recency effects in the continuousdistractor paradigm? There have been two approaches taken. One approach is to deny that recency effects in im-

This research was conducted while the first author was supported by the National Institute of Child Health and Human Development Mental Retardation Research Training Grant 5-T32-HD07176-12. Correspondence concerning this article should be addressed to R. L. Greene, Department of Psychology, Case Western Reserve University, Cleveland, $\mathrm{OH} 44106$. mediate recall and long-term recency effects in the continuous-distractor paradigm have a common basis. According to this approach, recency effects in these two tasks are unrelated phenomena (e.g., Schneider \& Detweiler, 1987). This approach appears unsatisfactory in light of the evidence that many variables (such as semantic similarity, word frequency, and list length) have similar influences on recency effects in these two tasks (Greene, 1986a; Greene \& Crowder, 1984).

An alternative approach is to claim that a short-termstore account can account for recency effects in both tasks. The most recent statement of this approach has been made by Koppenaal and Glanzer (1990; for similar viewpoints, see Nakajima \& Sato, 1989; Poltrock \& MacLeod, 1977). They pointed out that subjects in the continuous-distractor paradigm receive considerably more practice at the distractor task than those who perform the task only after the last item. Koppenaal and Glanzer suggested that subjects in the continuous-distractor paradigm might adapt to the distractor task so that they would be able to rehearse the items without impairing performance on the distractor task. This adaptation would accumulate across lists. Thus, a distractor task in the continuous-distractor paradigm might no longer fully occupy the short-term store.

Koppenaal and Glanzer (1990) reported one particularly striking piece of evidence in favor of their account. They performed an experiment in which one distractor task preceded the occurrence of every list item, and an entirely different distractor task filled the retention interval after the last item. No recency effects were found. Koppenaal and Glanzer argued that the subjects had had no opportunity to become habituated to the new distractor task occurring after the last item. Thus, this second distractor task was able to prevent maintenance of list items in the short-term store.

Koppenaal and Glanzer's (1990) short-term-store account of recency effects is tested in the experiments re- 
ported here. In the first three experiments, we tested the notion that adaptation to a distractor task is responsible for the presence of recency effects in the continuousdistractor paradigm. In Experiment 1, we examine the claim that the amount of exposure subjects have to a distractor task influences its effectiveness.

\section{EXPERIMENT 1}

Koppenaal and Glanzer (1990) suggested that subjects might habituate to a distractor task, rendering it ineffective in preventing maintenance of list items in a shortterm store. In this experiment, we tested the claim that prolonged exposure to a distractor task reduces its effectiveness. Subjects received lists of word pairs. Each list was followed by a distractor task requiring mental addition. Half of the subjects received extended practice at the task before seeing any of the lists, while the others received a shorter practice session.

\section{Method}

Subjects. Twenty-four students from introductory psychology classes participated to fulfill a course requirement. They were tested individually.

Procedure. All stimuli were presented on a Macintosh Plus computer. Each subject was first given practice at the addition distractor task. In this task, a four-term addition equation (e.g., $1+5+3=9$ ) appeared on the screen. All of the addends were between 1 and 9 . Half of the equations were true, and the remaining equations displayed a sum that was too high or low by two. The subject was instructed to read aloud the sum printed on the screen and to respond "true" or "false." Equations appeared at a 2-sec rate; an experimenter monitored compliance. Responses were recorded on audiotape and later scored. Half of the subjects (the shortpractice group) were given $20 \mathrm{sec}$ (10 equations) of practice at this task. The remaining subjects (the long-practice group) performed this task for $240 \mathrm{sec}$ (120 equations) as practice.

After this practice was completed, the subjects received 10 word lists, each composed of six word pairs. All the words used were common nouns, and the serial position of pairs on a list was counterbalanced across subjects. Each word pair was shown for $2 \mathrm{sec}$, and the subjects were required to read each of the words aloud. The last word pair on a list was followed by $20 \mathrm{sec}$ (10 equations) of the addition distractor task. After this filled retention interval was completed, the subjects were prompted to recall the items, in any order, by typing them into the computer. When the subject could not recall any more words, the next list was presented until all 10 lists had been given.

\section{Results}

The results from the word-recall phase are shown in Figure 1 . The number of words recalled was used as the primary dependent variable in the analyses. Since two words were presented at each position, a subject's score at each position on one list could be 0,1 , or 2 . The first question to ask is whether practice at the task had any effect on recall. It is clear from Figure 1 that it did. At all positions, performance was higher for the long-practice group than for the short-practice group. However, there was no sign of a recency effect in either group. Even after extended practice, a distractor task can still eliminate recency effects. An analysis of variance (ANOVA)

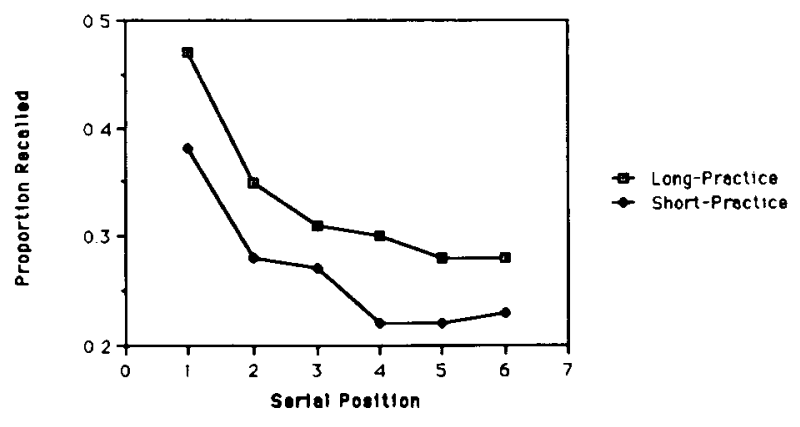

Figure 1. The proportion of items recalled at each serial position in Experiment 1 as a function of practice at the distractor task.

showed a significant effect of practice group $[F(1,22)=$ $\left.7.92, M S_{\mathrm{e}}=6.32\right]$ and serial position $[F(5,110)=8.30$, $\left.M S_{\mathrm{e}}=4.94\right]$, but no interaction $(F<1.0)$. (This analysis, and all subsequent ones, used a .05 significance level.)

Why did practice at the distractor task affect overall recall with no specific impact on the recency positions? One possibility (suggested by the reasoning of Bjork \& Allen, 1970) is that well-practiced distractor tasks might lead to less contextual change during the retention interval than poorly practiced tasks. Since subjects may use contextual cues to retrieve all list items, and the effectiveness of these cues will depend on the similarity between encoding and retrieval contexts, the effect of distractortask difficulty would extend throughout the list.

\section{EXPERIMENT 2}

Koppenaal and Glanzer (1990) claimed that "the special character of the continuous-distractor task, with repeated, extensive practice on the distractor task, reduces the displacement effects of the distractors and produces a time sharing that allows the subject to hold several items across the distractors'' (p. 187). Koppenaal and Glanzer (p. 188) specifically assume that practice effects accumulate over lists in this paradigm. Experiment 1 showed no evidence that practice on the distractor task reduces the displacement effect of the task. However, a crucial requirement may be that subjects are trying to remember items while performing the distractor task. Possibly, recency effects in the continuous-distractor task do not reflect practice at the task, but rather practice at timesharing, dividing attention between the task and the last few list items. Initially, subjects might not be able to perform this time-sharing very well, but they might improve with practice.

There are already experiments in the literature that can be considered tests of this proposition. Glenberg, Bradley, Kraus, and Renzaglia (1983, Experiments 1 and 2) had subjects participate in two phases. In the first phase, they received three continuous-distractor lists. These could be expected to exhibit a long-term recency effect and (by Koppenaal \& Glanzer's, 1990, reasoning) would indicate that the subjects had learned how to perform the distrac- 
tor task and to rehearse the last few list items simultaneously. In the second phase, the subjects received three lists on which the distractor task occurred only at the end. If they had mastered a time-sharing strategy, then one would expect to find a large recency effect here as well. In fact, the subjects exhibited a strong long-term recency effect on the continuous-distractor lists in the first phase, but no sign of a recency effect in the second phase.

We thought it important to replicate Glenberg et al.'s (1983) experiments. Also, that study was conducted for different purposes and may not be ideal as a test of Koppenaal and Glanzer's (1990) hypothesis. Specifically, the continuous-distractor lists were always presented before the lists containing distraction only at the end. Thus, condition was confounded with amount of practice at recalling lists. We conducted an experiment (Experiment 2) that is conceptually similar to Glenberg et al.'s, but with the order of the conditions counterbalanced.

\section{Method}

Subjects. Forty-eight students from introductory psychology classes participated to fulfill a course requirement.

Design. All the subjects received 10 lists. On 5 of the lists, they were shown six pairs of words and were then required to perform a 20-sec distractor task; this condition is referred to here as the end-only condition, because the distractor task occurred only at the end of the list. On the other 5 lists, the subjects had to perform the 20 -sec distractor task before and after every word pair; this is the continuous-distractor paradigm as developed by Bjork and Whitten (1974). The end-only and continuous-distractor conditions were blocked, and their order was counterbalanced across subjects.

Procedure. All the subjects received $20 \mathrm{sec}$ of practice on the addition distractor task that was used in Experiment 1. Half of the subjects then received the end-only condition. The procedure on each six-pair list was identical to that followed in Experiment 1. The other subjects began with the continuous-distractor condition and were required to perform the addition task for $20 \mathrm{sec}$ before every word pair as well as after the last word pair. After the first five lists were completed, the subjects were given instructions appropriate for the other condition, and were then given five more lists. As in Experiment 1, they were required to read the items aloud. The serial position of the word pairs was counterbalanced across subjects. Unlike Experiment 1, performance on the addition distractor task was not audiotaped, but was scored on line by the experimenter.

\section{Results}

The recall results from those subjects who received the continuous-distractor lists before the end-only lists are shown in Figure 2. The results from those who received the end-only lists first are shown in Figure 3 . The data from both orders are quite similar. There were strong recency effects in the continuous-distractor condition, but there was little sign of a recency effect in the end-only condition.

Insofar as Koppenaal and Glanzer's (1990) hypothesis only makes clear predictions for the subjects who received the continuous-distractor lists before the end-only lists, the two orders were analyzed separately. For the subjects who received the continuous-distractor lists first, there was no effect of condition $(F<1.0)$, but there was a significant effect of serial position $[F(5,115)=15.47$,

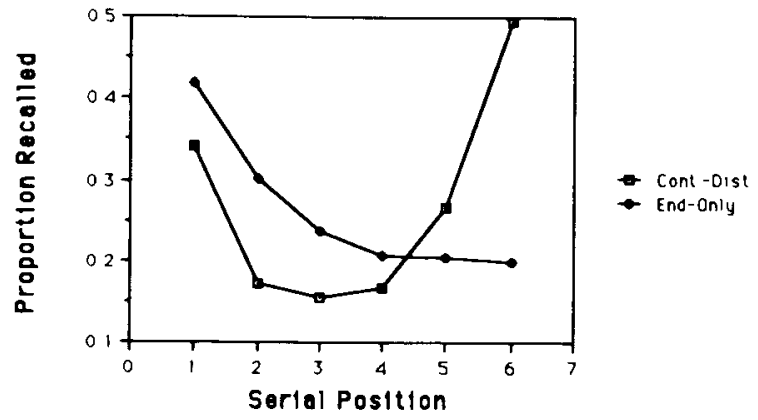

Figure 2. The proportion of items recalled at each serial position in Experiment 2 by subjects who received continuous-distractor lists before end-only lists.

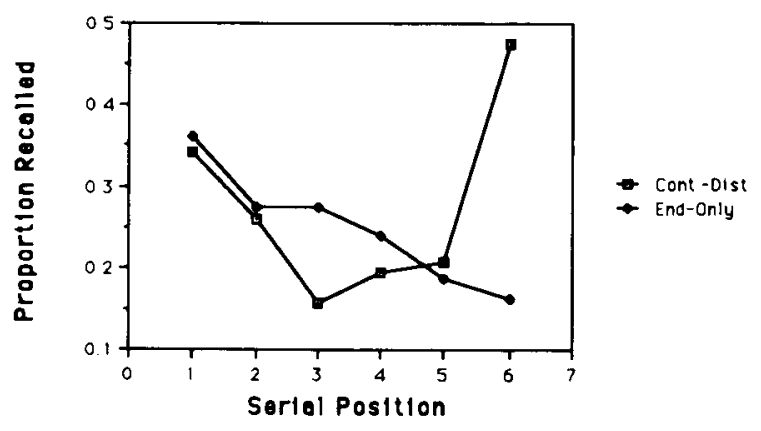

Figure 3. The proportion of items recalled at each serial position in Experiment 2 by subjects who received end-only lists before continuous-distractor lists.

$\left.M S_{\mathrm{e}}=1.96\right]$ and a significant interaction between serial position and condition $\left[F(5,115)=15.97, M S_{\mathrm{e}}=1.86\right]$. When the last serial position was analyzed separately, it was found that the continuous-distractor condition led to higher recall there than in the end-only condition $\left[F(1,23)=48.71, M S_{e}=2.22\right]$.

Similarly, for the subjects who received the end-only lists first, there was no effect of condition $[F(1,23)=$ $1.03, M S_{\mathrm{e}}=3.69$ ], a significant effect of serial position $\left[F(5,115)=11.34, M S_{\mathrm{e}}=1.66\right]$, and a significant interaction between condition and serial position $[F(5,115)=$ $\left.15.04, M S_{\mathrm{e}}=1.77\right]$. Analysis at the last serial position showed higher recall in the continuous-distractor condition than in the end-only condition $[F(1,23)=70.35$, $\left.M S_{e}=1.67\right]$.

Experiment 2 showed no evidence that the amount of practice subjects had in time-sharing between the distractor task and retaining list items influenced the magnitude of the recency effect. Rather, those in the continuousdistractor condition showed recency effects, and those who received distractor activity only at the end of a list did not.

\section{EXPERIMENT 3}

In this experiment, we followed a logic similar to that used in Experiment 2. Imagine a subject who goes through 
three lists in the continuous-distractor paradigm, in which each list position is preceded and followed by a distractor task (Task A). This subject would be expected to exhibit a substantial recency effect. By Koppenaal and Glanzer's (1990) reasoning, this subject must have adapted to the distractor task and can thus rehearse items, even while performing the task. Then, the subject is put into a condition similar to that of Koppenaal and Glanzer, and is required to perform a novel distractor task (Task B) before each of the word pairs. During the retention interval after the last word pair, subjects are required to perform Task A. According to Koppenaal and Glanzer, subjects must have already learned how to perform Task A while rehearsing the list items. Thus, they should show a recency effect here that is at least as large as that found in the first three lists.

In other words, in this experiment, the subjects again go through two blocks of lists. In one block, they go through a standard continuous-distractor condition, in which a single distractor task occurs before each word pair and after the last word pair. In the other block, the subjects perform one distractor task before each word pair and a different one after the last word pair. The distractor task used after the last word pair is the same one that had been used in the continuous-distractor lists. As in Experiment 2 , the order of the two blocks was counterbalanced across subjects.

\section{Method}

Subjects. Forty-eight students from introductory psychology classes participated to fulfill a course requirement.

Procedure. There were two distractor tasks used. One was the same addition task that had been used in the first two experiments, and the other involved naming letters. Uppercase letters appeared one at a time on the computer screen at a 500-msec rate, and the subjects were required to read each letter aloud. They performed this task for $20 \mathrm{sec}$. Performance on these distractor tasks was recorded on audiotape and later scored.

There were four groups of subjects. One group first received three lists with which they performed the addition task before each word pair and after the last word pair (the continuous-distractor condition); they then received three lists and performed the letter-naming task before each word pair and the addition task after the last word pair (a switch condition, patterned after Koppenaal \& Glanzer, 1990). A second group of subjects first received three continuousdistractor lists and performed the letter-naming task before each word pair and after the last word pair; they then received three "switch" lists, and performed the addition task before each word pair and the letter-naming task after the last word pair. A third group of subjects first received three switch lists, and performed the addition task before each word pair and the letter-naming task after the last word pair; they then received three continuous-distractor lists with which they named letters before and after each word pair. Finally, a fourth group of subjects received three switch lists, and performed the letter-naming task before each word pair and the addition task after the last word pair; they then received three continuous-distractor lists and performed the addition task before and after each word pair.

As in the first two experiments, all the lists were composed of six word pairs presented for $2 \mathrm{sec}$, and the subjects were required to read them aloud.

\section{Results}

Koppenaal and Glanzer's (1990) hypothesis predicts that recency effects would be found in the switch condition when those lists follow the continuous-distractor condition, but the results of Experiment 3 refute this prediction. Recency effects were always found in the continuousdistractor condition and never found in the switch condition. The results are shown in Figure 4 for the subjects who received the continuous-distractor lists first and in Figure 5 for those who received the switch lists first.

For the subjects who received the continuous-distractor condition before the switch condition, there was a nonsignificant effect of condition $\left[F(1,23)=2.43, M S_{\mathrm{e}}=\right.$ 3.03], a significant effect of serial position $[F(5,115)=$ 9.85, $\left.M S_{\mathrm{e}}=1.64\right]$, and a significant interaction between condition and serial position $\left[F(5,115)=13.96, M S_{\mathrm{e}}=\right.$ $1.50]$. When the last position was analyzed separately, recall was higher in the continuous-distractor condition than in the switch condition $\left[F(5,115)=74.41, M S_{\mathrm{e}}=\right.$ $0.85]$.

A similar pattern was found with the subjects who received switch lists before continuous-distractor lists. There was a nonsignificant effect of condition $(F<1.0)$, a significant effect of serial position $[F(5,115)=12.29$, $\left.M S_{\mathrm{e}}=1.28\right]$, and a significant interaction between these

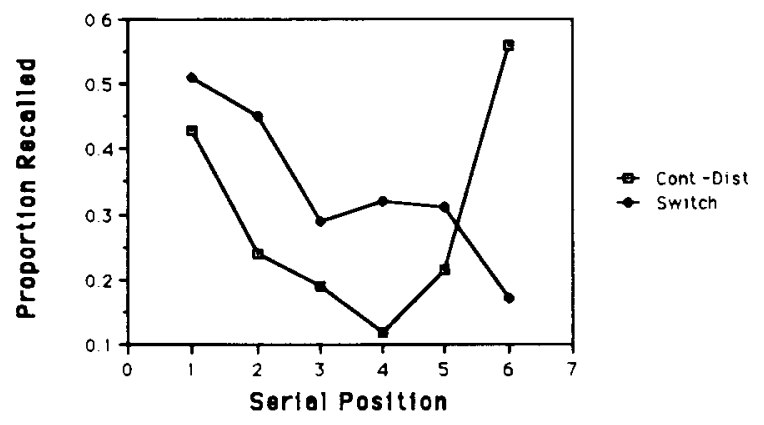

Figure 4. The proportion of items recalled at each serial position in Experiment 3 by subjects who received continuous-distractor lists before switch lists.

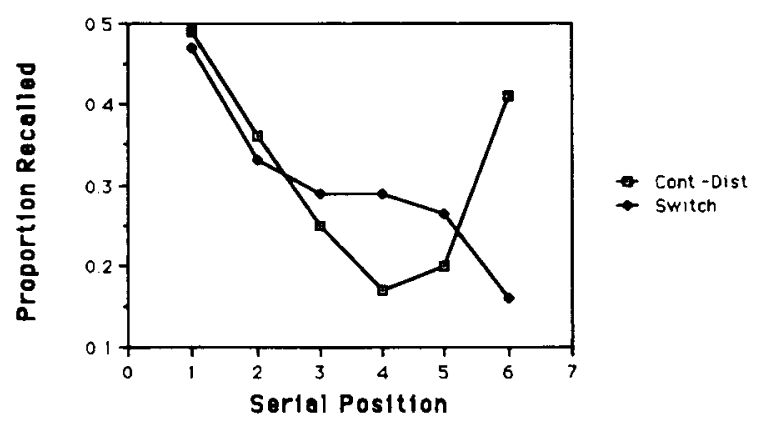

Figure 5. The proportion of items recalled at each serial position in Experiment 3 by subjects who received switch lists before continuous-distractor lists. 
two factors $\left[F(5,115)=6.52, M S_{\mathrm{e}}=1.00\right]$. Recall at the sixth position was higher in the continuous-distractor condition than in the switch condition $[F(1,23)=25.27$, $M S_{\mathrm{e}}=0.95$ ].

We noticed that the switch condition seemed to lead not only to an elimination of the recency effect, but also to a clear drop in recall at the last position. We wanted to examine this pattern further in Experiment 4. We also wanted to see whether a switch in the distractor task always leads to a decrement in recall at the preceding position. Therefore, we also included a condition in which there was a switch in distractor task after the fifth position, rather than after the last (sixth) position.

\section{EXPERIMENT 4}

\section{Method}

Subjects. Thirty-six students from introductory psychology classes participated to fulfill a course requirement.

Procedure. All the subjects received 10 lists. Half of them received lists with which they performed the letter-naming task for $20 \mathrm{sec}$ before each of the six word pairs, and the addition task for $20 \mathrm{sec}$ after the last word pair. The other subjects received lists with which they performed the letter-naming task before the first five word pairs, but performed the addition task after the fifth and sixth pairs. In all other respects, the procedure followed that of the previous experiments. Performance on the distractor tasks was recorded on audiotape.

\section{Results}

As is evident in Figure 6, there appears to be a sudden one-position drop in recall for the word pair immediately preceding the switch in distractor task. An overall ANOVA showed a nonsignificant effect of condition $(F<1.0)$, a significant effect of serial position $[F(5,170)=10.33$, $\left.M S_{\mathrm{e}}=3.02\right]$, and a significant interaction of condition and serial position $\left[F(5,170)=6.41, M S_{e}=3.02\right]$. For the subjects who had a switch in distractor task after the last word pair, the drop from the fifth to the sixth position was significant $\left[F(1,17)=6.50, M S_{e}=4.11\right]$. For the subjects who had a switch in distractor task after the fifth word pair, there was a significant drop from the fourth to the fifth pair $\left[F(1,17)=13.60, M S_{\mathrm{e}}=3.95\right]$.

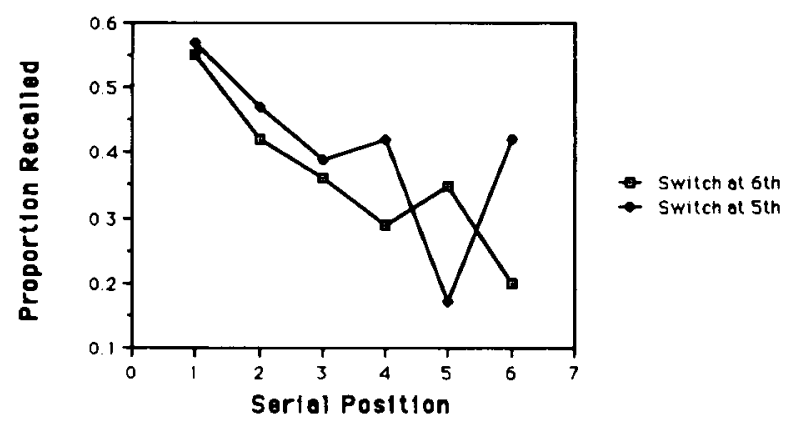

Figure 6. The proportion of items recalled at each serial position in Experiment 4 as a function of whether the distractor task changed following the fifth or sixth item.
Experiment 4 was not motivated by a strong hypothesis; rather, we were following up on an observation from Experiment 3 . However, the finding that switching distractor tasks leads to a one-position drop in recall puts Koppenaal and Glanzer's (1990) finding, that switching distractor tasks after the last item eliminates the recency effect, in a different light. Possibly, Koppenaal and Glanzer's finding did not result from preventing adaptation to a distractor task, but rather from disrupting memory by switching distractor tasks. This can be examined by having subjects perform a different distractor task after every item. If switching distractor tasks disrupts memory, then this should equate disruption at all positions.

\section{EXPERIMENT 5}

\section{Method}

Subjects. Forty-eight students from introductory psychology classes participated to fulfill a course requirement.

Distractor tasks. Seven different distractor tasks were employed. Each of them was $20 \mathrm{sec}$ long and was presented on a Macintosh Plus computer. One was the addition task used in all the previous experiments, and another was the letter-naming task, also used in Expertments 3 and 4 . In the left-right task, the subjects saw a single parenthesis every $500 \mathrm{msec}$ and had to indicate if it was a lefthand or right-hand parenthesis. In the asterisk-counting task, they saw a column of from 3 to 10 asterisks every $500 \mathrm{msec}$, and had to say exactly how many were in the column. In the male-female task, the subjects saw a common name for $500 \mathrm{msec}$ and had to say whether it was a male or female name; in all, a set of 40 names was used. In the same-different task, the subjects saw an uppercase letter and a lowercase letter for $500 \mathrm{msec}$ and had to say whether the letters had the same name or a different name; although all 26 letters were used, same- and different-name pairs were equally probable. In the above-below task, the subjects saw an " $X$ " either above or below a sentence every $500 \mathrm{msec}$. The sentence shown was "Is the X above or below this sentence?" and the subjects had to respond "above" or "below."

Procedure. All the subjects received $20 \mathrm{sec}$ of practice on each of the distractor tasks, then went through 10 lists. Half of the subjects received a distractor task before and after every word pair (a continuous-distractor condition). The computer randomly chose distractor tasks under the restriction that each task occur once on each list. The other subjects received a distractor task only after the last word pair (the end-only condition). The computer randomly chose the distractor task that occurred on a list under the restriction that each subject receive each task at least once in the experiment, and no more than twice.

As in the previous experiments, all the lists consisted of six word pairs, and the subjects were required to read the words aloud. Word pairs were counterbalanced across subjects with respect to serial position.

\section{Results}

As is shown in Figure 7, when a distractor task occurred only at the end of a list, the recency effect was eliminated, replicating the classic findings of Postman and Phillips (1965) and Glanzer and Cunitz (1966). However, in the continuous-distractor condition, using a different distractor task before each position and after the last position, there was clearly a recency effect. An overall ANOVA showed no main effect of condition $(F<1.0)$, a signifi- 


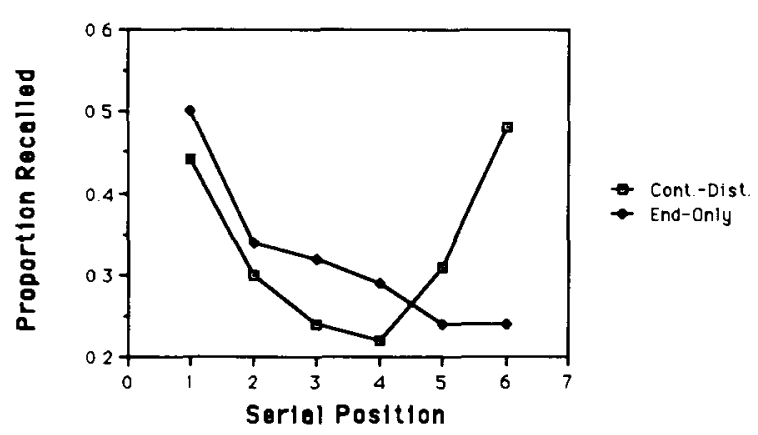

Figure 7. The proportion of items recalled at each serial position in Experiment 5. Seven different distractor tasks were used in the continuous-distractor condition.

cant effect of serial position $\left[F(5,230)=14.16, M S_{\mathrm{e}}=\right.$ $2.21]$, and a significant interaction between condition and position $\left[F(5,230)=8.28, M S_{\mathrm{e}}=2.21\right]$. At the last position, the continuous-distractor condition led to significantly higher recall than the end-only condition, $\left[F(1,46)=24.75, M S_{\mathrm{e}}=2.74\right]$.

\section{GENERAL DISCUSSION}

Koppenaal and Glanzer (1990) found that the long-term recency effect in the continuous-distractor paradigm was eliminated when one distractor task was used before each position and a different task was used after the last position. They argued that long-term recency effects are found only if subjects have the opportunuty to adapt to the distractor task, thereby allowing them to perform the task while rehearsing the list items. The present study has reported several pieces of evidence against this claim. First, we found in Experiment 1 that practice at a distractor task did not affect its effectiveness at eliminating the recency effect, but simply made a task easier, which led to improved recall at all positions. Second, in Experiment 2, we found that a distractor task that occurred only at the end of a list eliminated recency effects, even if the subjects had already gone through continuous-distractor lists utilizing that same task. In Experiment 3, we found that switching distractor tasks after the last position eliminated the recency effect, even if the subjects had already had considerable exposure to the task occurring after the last position. The results of Experiment 4 suggest that switching distractor tasks can disrupt memory in ways other than simply preventing adaptation. Indeed, in Experiment 5 we found a recency effect when a different distractor task occurred before and after every position.

\section{Performance on Distractor Tasks}

One possible explanation for these data has not yet been addressed: The pattern of recency effects might reflect complex tradeoffs in attention between the distractor tasks and the word lists. Since performance on the distractor tasks has not usually been reported in studies of long-term recency effects, an account of this sort might apply to the previous literature as well. To address this account, performance on the distractor tasks in all the experiments was recorded. In Experiment 2, performance was recorded by the experimenter on line as the subject carried out the tasks. In the other experiments, task performance was recorded on a cassette audiotape and was scored later.

There are several concerns that one might have about the tasks. First, one might worry that the subjects did not actually carry out the tasks. However, all the subjects in all the experiments performed the tasks at higher-thanchance levels. A second concern might be that the tasks were too easy. However, no subject in any of the experiments performed at $100 \%$ accuracy. In the addition task that was used in all of the experiments, the proportion of problems responded to correctly ranged from .63 to .87 for individual subjects. In the letter-naming task used in Experiments 3, 4, and 5, the proportion of letters correctly read ranged from .53 to .82 . In the left-right task, the asterisk-counting task, the male-female task, the same-different task, and the above-below task used only in Experiment 5, performance for individual subjects ranged from .64 to $.81, .60$ to $.77, .67$ to $.89, .71$ to .87 , and .75 to .92 , respectively. The range of performance on the different tasks did not vary widely, because considerable piloting had been performed to ensure that these tasks were roughly comparable in performance level.

When ANOVAs were conducted on distractor-task performance, there was no evidence that the serial-position curves reflected tradeoffs between the tasks and the list items. In none of the analyses was there a significant effect of serial position on task performance in the continuous-distractor conditions in Experiments 2, 3, 4, or 5 (in all cases, $p>.20$ ). (All of these analyses were performed on the number of distractor problems answered correctly.) Similarly, there is no evidence that the presence of recency effects in some conditions, but not others, was the result of differential performance of the distractor tasks. Analyses were performed in each experiment on the number of distractor problems answered correctly during the retention interval following presentation of the last item. Experiment 1 was the only experiment in which the experimental conditions differed in the proportion of distractor stimuli responded to correctly during the retention interval. There, as would be expected, the longpractice group (.80) performed more accurately than the short-practice group $(.67)\left[F(1,22)=15.76, M S_{\mathrm{e}}=\right.$ 43.98]. This occurred even though there was no recency effect in either group. Thus, recency effects do not seem to reflect a tradeoff between the performance of the distractor tasks and attending to the list items.

\section{Alternative Short-Term-Store Accounts}

If it is conceded that these experiments make Koppenaal and Glanzer's (1990) account appear unlikely, one might still hope that other short-term-store accounts might prove 
more satisfactory. Obviously, we are not claiming to have disproven all such accounts that might be developed in the future. However, we have doubts as to whether any short-term-store account will offer a satisfactory account of recency effects in free recall.

One reason for our skepticism about the viability of short-term-store accounts is that recency effects may arise in many circumstances in long-term recall; even Koppenaal and Glanzer (1990, p. 194) concede that it is unlikely that short-term-store accounts could ever be modified to account for all of these findings. For example, Glenberg et al. (1983, Experiment 5) demonstrated massive recency effects, even when the retention interval was 1 day long. Presumably, the subjects in that experiment were not continuously maintaining items in a short-term store for a complete day. Although short-term-store accounts seem inherently unable to account for findings such as these, the chief alternative approach, retrieval accounts, are largely consistent with the range of data reported on recency effects in free recall.

Moreover, current short-term-store accounts do not offer a satisfactory explanation for recency effects, even in immediate recall (see Greene, 1986b, for a review). One particularly critical finding is that concurrent distractor activity carried on during presentation of list items does not reduce the magnitude of the recency effect (e.g., Baddeley \& Hitch, 1977). If an account proposes that a distractor activity can occupy the short-term store when it occurs after a list, it is difficult to see why it should not at least partially occupy that store when it is occurring at the same time as list presentation.

M. J. Watkins and Peynircioglu (1983) reported another finding that is inconsistent with short-term-store accounts of recency effects in immediate free recall. They gave their subjects lists of 45 items. Each list contained sublists of 15 stimuli, and each sublist consisted of a unique class of stimuli. For example, the sublists might be sounds, objects, and riddles. The three sublists alternated throughout the list. Immediate free recall for each of the three sublists showed a recency effect that was as extensive as that that would be found for any of the sublists presented alone. A short-term-store account could not explain these data without making the unlikely assumption that the capacity of a short-term store is somehow tripled in this situation.

\section{Retrieval Accounts of Recency Effects in Free Recall}

The chief alternative accounts of recency effects have stressed the importance of retrieval. Let us first explain the similarities between these accounts and short-termstore accounts. There is general agreement that the shape of the serial position curve reflects the operation of two distinct processes. One process is predominantly responsible for recall of early and middle items, and is very sensitive to the amount of associative processing that subjects have carried out on the items. Thus, factors such as interitem similarity (e.g., Craik \& Levy, 1970; Greene
\& Crowder, 1984) and word frequency (Greene, 1986a; Raymond, 1969; Sumby, 1963) can affect recall of early and middle items, presumably by facilitating associative processing. The fact that inserting filled intervals between items impairs recall of early and middle items (shown by Bjork \& Whitten, 1974, and evident in the data reported here) could be explained similarly; presumably, it becomes difficult to associate stimuli together when they are separated by filled intervals. Neither short-term-store accounts nor retrieval accounts have addressed the nature of this first process in much detail. There is also agreement that there is a second process in recall that is less likely to be influenced by the amount of associative processing, and that this second process is responsible for recency effects.

Retrieval accounts differ from short-term-store accounts in their definitions of the nature of these two distinct processes. Whereas short-term-store accounts consider these two processes as reflecting retrieval from a long-term store and a short-term store, retrieval accounts view these two processes as separate retrieval processes from a single memory system. Bjork and Whitten (1974) argued that recency effects are found when list items constitute a wellordered series, that is, when each item is coded in memory in terms of its serial position. The continuousdistractor task keeps the items separated by inserting distractor activity between them; this will tend to keep their ordering distinct for a longer period of time. Subjects then use ordinal information to retrieve the last few items on a list, while relying on other information (presumably interitem associations) to retrieve earlier items. Glenberg and his associates (Glenberg et al., 1980, 1983; Glenberg $\&$ Swanson, 1986) have proposed a related account. This approach also claims that distinct retrieval processes are used for early and late items and attributes long-term recency effects to an increase in retrievability for the last item, when items are separated in time.

Since these retrieval approaches do not assign any particular importance to practice at the distractor task, they are consistent with all the data reported here concerning recency effects. That is, retrieval accounts claim that the magnitude of the recency effect will be determined by the temporal relations among the items (i.e., whether or not they are spaced apart in time), and not by the amount of practice that subjects have had at the distractor task. This claim opposes Koppenaal and Glanzer's (1990) assumption that it is the amount of practice on the distractor task, and not the temporal distribution of the items, that is crucial in this paradigm. The results from all five experiments support the retrieval accounts on this crucial point.

For example, retrieval accounts would predict that there would be no recency effect in Experiment 1, because there are no filled intervals between items. Since these accounts are intended to explain recency effects, they would not make any strong predictions regarding overall differences in recall level between long-practice and short-practice conditions. However, they are certainly consistent with the speculative proposal we offered above, that more con- 
textual change may occur during an interval of a difficult (or poorly practiced) task than during an interval filled with an easy (or well-practiced) task. This would then lead to overall performance differences between the conditions.

Retrieval accounts predict that recency effects should be found whenever the list items are widely distributed in time. However, why does switching the nature of the distractor task after the last item lead to an elimination of the recency effect (Koppenaal \& Glanzer, 1990)? The results of Experiment 4 suggest that this reflects a general tendency for recall to be impaired at the position before a change in distractor task. Our data do not indicate the cause of this impairment, and, since it seems that this impairment is not specific to the terminal items, it is not clear that it should be explained by accounts of the recency effect. We would like to offer one speculation, however.

An important component of some theories of recency effects is cue overload (O. C. Watkins \& M. J. Watkins, 1975). Glenberg and his associates (Glenberg et al., 1980, 1983; Glenberg \& Swanson, 1986) have argued that the cues used to recall terminal items are contextually or temporally specific, so these cues tend to access only the terminal items. These cues are thus more effective than the broader cues used to retrieve other list items. However, this assumption can apply only if list items are somehow kept segregated from the stimuli perceived and encoded during the distractor task. In other words, if retrieval cues access distractor stimuli as well as list items, they are likely to become overloaded regardless of the serial position of the items or the temporal spacing of the list.

By this reasoning, the consistent alternation of list items and distractor stimuli is important for letting subjects organize these two classes of events into separate groups in long-term memory. The distractor stimuli are thus kept separate and do not become associated with the temporal or contextual cues used to retrieve terminal items. However, the formation of this organization can be impaired if there is a shift in the nature of the distractor task during list presentation. When such a shift occurs, the new distractor stimuli might be grouped with the immediately preceding list items, thereby lessening the chance of retrieval of those items. According to this speculative account, Koppenaal and Glanzer's (1990) discovery that long-term recency effects are eliminated by a shift in distractor tasks reflects an overloading of retrieval cues used to recall terminal items, and not the operation of a shortterm store. There is some prior evidence supporting these speculations. Greene (1985) showed that recency effects in long-term recall can be eliminated if distractor stimuli and list items are not consistently separated into distinct classes. A cue-overload interpretation was used to account for those findings.

How would this account explain the finding in Experiment 5 that recency effects may be found when a different distractor task is used after every position? There seem to us to be two possibilities. First, these shifting tasks are still impairing recall, but because these impairments are equated across position, the original recency advantage reappears. Second, when these distractor shifts are always occurring before and after every item, subjects are able to group distractor stimuli and list stimuli into separate organizations in memory.

\section{Conclusion}

Certain aspects of our data must still be explained in a purely speculative fashion (especially the effect of practice on overall recall in Experiment 1, and the effect of changing distractor tasks in Experiments 3, 4, and 5). However, we now have evidence that the short-term-store proposal of Koppenaal and Glanzer (1990) is not satisfactory. All of the results regarding recency effects in our data are consistent with retrieval accounts of long-term recency effects. It seems likely that a long-term explanation will be needed to account for long-term recency effects.

\section{REFERENCES}

Atkinson, R. C., \& Shiffrin, R. M. (1968). Human memory: A proposed system and its control processes. In K. W. Spence \& J. T. Spence (Eds.), The psychology of leaming and motivation (Vol. 2 , pp. 89-105). New York: Academic Press.

Baddeley, A. D., \&itch, G. J. (1977). Recency re-examined. In S. Dornic (Ed.), Attention and performance (Vol. 6, pp. 647-667), Hilisdale, NJ: Erlbaum.

Bjork, R. A., \& AlleN, T. W. (1970). The spacing effect: Consolidation or differential encoding? Journal of Verbal Learning \& Verbal Behavior, 9, 567-572.

Bjork, R. A., \& Witten, W. B. (1974). Recency-sensitive retrieval processes in long-term free recall. Cognitive Psychology, 6, 173-189.

Craik, F. I. M., \& Levy, B. A. (1970). Semantic and acoustic information in primary memory. Joumal of Experimental Psychology, 86, 77-82.

Glanzer, M. (1972). Storage mechanisms in recall. In G. H. Bower (Ed.), The psychology of learning and motivation (Vol. 5, pp. 129193). New York: Academic Press.

Glanzer, M., \& Cunitz, A. R. (1966). Two storage mechanisms in free recall. Journal of Verbal Learning \& Verbal Behavior, 5, 351-360.

GlenberG, A. M., Bradley, M. M., Kraus, T. A., \& Renzaglia, G. J. (1983). Studies of the long-term recency effect: Support for a contextually guided retrieval hypothesis. Joumal of Experimental Psychology: Learning, Memory, \& Cognition, 9, 231-255

Glenberg, A. M., Bradley, M. M., Stevenson, J. A., Kraus, T. A., Tkachuk, M. J., Gretz, A. L., Fish, J. H., \& Turpin, B. M. (1980). A two-process account of long-term serial position effects. Journal of Experimental Psychology: Human Learning \& Memory, 6, 355-369.

GlenberG, A. M., \& Swanson, N. G. (1986). A temporal distinctiveness theory of recency and modality effects. Journal of Experimental Psychology: Learning, Memory, \& Cognition, 12, 3-15.

Greene, R. L. (1985). Constraints on the long-term modality effect. Journal of Memory \& Language, 24, 526-541.

Greene, R. L. (1986a). A common basis for recency effects in immediate and delayed recall. Journal of Experimental Psychology: Learning, Memory, \& Cognition, 12, 413-418.

Greene, R. L. (1986b). Sources of recency effects in free recall. Psychological Bulletin, 99, 221-228.

Greene, R. L., \& Crowder, R. G. (1984). Effects of semantic similarity on long-term recency. American Journal of Psychology, 97, 441-449. 
Koppenaal, L., \& Glanzer, M. (1990). An examination of the continuous distractor task and the "long-term recency effect." Memory \& Cognition, 18, 183-195.

Nakajima, Y., \& SaTo, K. (1989). Distractor difficulty and the longterm recency effect. American Journal of Psychology, 102, 511-521.

Poltrock, S. E., \& Macleod, C. M. (1977). Primacy and recency in the continuous distractor paradigm. Journal of Experimental Psychology: Human Learning \& Memory, 3, 560-571.

Postman, L., \& Phillips, L. W. (1965). Short-term temporal changes in free recall. Quarterly Journal of Experimental Psychology, 17, 132-138.

RAYMOND, B. (1969). Short-term storage and long-term storage in free recall. Journal of Verbal Learning \& Verbal Behavior, 8, 567-574

SCHNeIder, W., \& DeTweIler, M. (1987). A connectionist/control architecture for working memory. In G. H. Bower (Ed.), The psychology of learning and motivation (Vol. 21, pp. 53-119). New York: Academic Press.
Sumby, W. H. (1963). Word frequency and serial position effects. Journal of Verbal Learning \& Verbal Behavior, 1, 443-450.

Tzeng, O. J. L. (1973). Positive recency effects in delayed free recall. Journal of Verbal Learning \& Verbal Behavior, 12, 436-439.

Watkins, M. J., \& PeYnircioglu, Z. F. (1983). Three recency effects at the same time. Joumal of Verbal Leaming \& Verbal Behavior, 22, 375-384

WATKINS, O. C., \& WATKINS, M. J. (1975). Build-up of proactive inhibition as a cue-overload effect. Joumal of Experimental Psychology, 104, 442-452.

Waugh, N. C., \& Norman, D. A. (1965). Primary memory. Psychological Review, 72, 89-104.

(Manuscript received December 4, 1991; revision accepted for publication September 8, 1992.) 